\title{
Viabilidade, confirmação taxonômica e detecção enzimática de espécies de Acremonium preservadas sob óleo mineral na Coleção de Culturas University Recife Mycology
}

\author{
Viability, taxonomic confirmation and enzymatic detection of Acremonium \\ species preserved under mineral oil in the URM Culture Collection
}

\author{
Suellen Carvalho de Moura Braz ${ }^{1}$, Cristina Maria de Souza Motta ${ }^{1}$, \\ Débora Maria de Lima Massa ${ }^{1}$, Rejane Pereira Neves ${ }^{1}$ e Oliane Maria Correia Magalhães ${ }^{1}$
}

\begin{abstract}
RESUMO
Enzimas hidrolíticas secretadas por fungos têm um papel importante na patogenicidade das infecções. Objetivando avaliar a atividade enzimática foram testados 31 isolados de Acremonium mantidos na Coleção de Culturas University Recife Mycology. Fragmentos das culturas foram transferidos para caldo glicosado para reativação e posterior crescimento em meio ágar batata dextrose, para verificar viabilidade, pureza e confirmação taxonômica pela observação das características macroscópicas e microscópicas. Para detecção enzimática foram utilizados substratos de caseína do leite e gelatina para protease, amido para amilase e lecitina de soja para fosfolipase. Das 31 culturas, 26 (83,9\%) mantiveram-se viáveis e 24 (92,3\%) foram confirmadas taxonomicamente. Das 24 culturas, 12 (50\%) apresentaram atividade proteásica, duas (16,7\%) em caseína do leite, uma (8,3\%) em gelatina e nove (75\%) em ambos os substratos; 16 (66,7\%) degradaram amido. Nenhuma cultura apresentou atividade fosfolipásica. Conclui-se que espécies de Acremonium são capazes de produzir enzimas envolvidas na patogenicidade das infecções fúngicas.
\end{abstract}

Palavras-chaves: Acremonium. Protease. Amilase. Fosfolipase.

\begin{abstract}
Hydrolytic enzymes secreted by fungi play an important role in the pathogenesis of infection. With the aim of evaluating the enzymatic activity, 31 isolates of Acremonium stored in the University of Recife Mycology (URM) Culture Collection were tested. Culture fragments were transferred to glycoside broth for reactivation and further growth in potato dextrose agar medium in order to investigate viability and purity and to confirm the taxonomy through observing the macroscopic and microscopic characteristics. To detect enzymes, milk casein and gelatin were used as substrates for proteinase, starch for amylase and soy lecithin for phospholipase. Among the 31 cultures, 26 (83.9\%) remained viable and 24 (92.3\%) were confirmed taxonomically. Out of these 24 cultures, 12 (50\%) presented proteinase activity, of which two (16.7\%) were on milk casein, one (8.3\%) on gelatin and nine (75\%) on both substrates; 16 (66.7\%) degraded starch. None of the cultures presented phospholipase activity. It was concluded that Acremonium species are able to produce enzymes that are involved in the pathogenicity of fungal infections.
\end{abstract}

Key-words: Acremonium. Proteinase. Amylase. Phospholipase.

0 gênero Acremonium compreende sapróbios do solo dispersos no meio ambiente que podem ocasionar patologias em humanos como agentes etiológicos de micoses oportunistas e subcutâneas 5 . Nos últimos anos, o número e a diversidade de infecções causadas por espécies de Acremonium têm aumentado ${ }^{8}$, sendo também crescente 0 número de espécies citadas como agentes de infecções localizadas e disseminadas

1. Departamento de Micologia, Centro de Ciências Biológicas, Universidade Federal de Pernambuco, Recife, PE.

Suporte Financeiro: RENNEBRA-CNPq/MCT (Processo 552410/2005-5)

Endereço para correspondência: Dra. Oliane Maria Correia Magalhães. Rua Oliveira Fonseca 350/Apt ${ }^{\circ} 101$, Campo Grande, 52040-250 Recife, PE.

Fax: $55812126-8480$

e-mail: olimicomed@yahoo.com.br

Recebido para publicação em 13/08/2008

Aceito em 10/12/2008 em pacientes com condições predisponentes como doença de Addison's, neutropenia, imunossupressão e abuso de drogas intravenosas, entre outras ${ }^{158}$.

De acordo com Hoog e cols ${ }^{9}$ Acremonium curvulum foi relatado em endoftalmites, Acremonium kiliense em endoftalmites, hialohifomicoses, micetomas, ceratites, endocardites, peritonites e Acremonium strictum em peritonites e infecções pulmonares e invasivas em pacientes com neutropenia.

Fungos secretam muitas enzimas hidrolíticas em meios de cultura. Essas enzimas têm um papel importante no metabolismo fúngico, podendo estar envolvidas na patogenicidade da infecção, causando danos para as células hospedeiras e provendo nutrientes em um ambiente restrito ${ }^{15}{ }^{17}$.

Diante disto, o objetivo do presente estudo foi verificar a atividade enzimática de espécies de Acremonium mantidas na Coleção de Culturas University Recife Mycology (URM). 


\section{MATERIAL E MÉTODOS}

Culturas. Foram testadas um total de 31 culturas de Acremonium preservadas sob óleo mineral ${ }^{22}$ estocadas de 1964 a 2005 na Coleção de Culturas URM do Departamento de Micologia, Centro de Ciências Biológicas, Universidade Federal de Pernambuco (Tabela 1).

Reativação. Fragmentos das culturas preservadas foram transferidos para caldo glicosado e mantidos a $28^{\circ} \mathrm{C} \pm 2^{\circ} \mathrm{C}$. Após crescimento foram transferidas para ágar batata dextrose (BDA) para verificar viabilidade, pureza e confirmação taxonômica.

Confirmação taxonômica. Foram utilizadas características macroscópicas e microscópicas de acordo com Domsch e Gams ${ }^{4}$, Gams $^{6}$ e Hoog e cols?

Atividade enzimática. Após sete dias de crescimento de culturas de Acremonium em BDA, discos de cinco milímetros de diâmetro foram retirados e inoculados centralmente nos meios específicos para cada enzima.

Protease. A detecção de protease foi realizada utilizando caseína do leite e gelatina como substratos de acordo com Lacaz e $\operatorname{cols}^{12}$. 0 diâmetro da zona transparente ao redor das colônias em caseína do leite foi mensurado para determinar a zona de atividade (ZA). Para interpretação foram considerados: ZA entre 0.9 e $1(+)$ muito fraca, 0.89-0.80 (++) fraca, 0.79-0.70 (+++) forte e ZA menor que $0.69(++++)$ muito forte segundo Serda e $\mathrm{col}^{21}$ que adaptaram a interpretação do método de Price e cols ${ }^{16}$. De acordo com esse sistema, uma ZA fraca significa uma alta expressão da enzima, enquanto uma ZA forte indica baixa expressão.

Amilase. 0 meio de cultura ágar Czapek, modificado segundo Cordeiro Neto e cols ${ }^{3}$ recebeu os seguintes tratamentos: a) meio controle negativo $(\mathrm{CN})$ sem fonte de carbono $\left(\mathrm{NaNO}_{3} 3 \mathrm{~g}, \mathrm{MgSO}_{4}\right.$ $0,5 \mathrm{~g}, \mathrm{FeSO}_{4}+7 \mathrm{H}_{2} \mathrm{O} 0,01 \mathrm{~g}, \mathrm{~K}_{2} \mathrm{HPO}_{4} 1 \mathrm{~g}$, ágar $16 \mathrm{~g}$ e água destilada $1.000 \mathrm{~mL}$ ); b) meio controle positivo (CP) (meio $\mathrm{CN}$ adicionado

TABELA 1

Detecção enzimática de espécies de Acremonium mantidas na Coleção de Culturas University Recife Mycology (URM).

\begin{tabular}{|c|c|c|c|c|c|}
\hline Espécie /Registro (URM) & $\begin{array}{l}\text { Ano de } \\
\text { estoque }\end{array}$ & $\begin{array}{l}\text { Substrato/ } \\
\text { procedência }\end{array}$ & $\begin{array}{l}\text { Zona de } \\
\text { atividade }\end{array}$ & Gelatina & $\begin{array}{c}\text { Taxa de } \\
\text { crescimento }\end{array}$ \\
\hline Acremonium alternatum (1929) & 1964 & solo & NR & NR & NR \\
\hline Acremonium bacillisporum (3134) & 1989 & solo marinho & 0,82 & + & 109,5 \\
\hline Acremonium bacillisporum(4029) & 1998 & água & 0,88 & - & 114,7 \\
\hline Acremonium bacillisporum (5023) & 2005 & água da praia & 0,74 & + & 108,2 \\
\hline Acremonium charticola (3785) & 1997 & solo & NR & NR & NR \\
\hline Acremonium curvulum (3959) & 1998 & rizosfera de girassol & - & - & 130,0 \\
\hline Acremonium curvulum (4695) & 2003 & solo & 0,95 & + & 110,0 \\
\hline Acremonium furcatum (3823) & 1997 & água de açude & - & - & 102,0 \\
\hline Acremonium fusidioides(3563) & 1994 & aveia & NR & NR & NR \\
\hline Acremonium fusidioides(3759) & 1997 & solo & - & - & 105,6 \\
\hline Acremonium fusidioides (3847) & 1997 & solo & - & - & 94,7 \\
\hline Acremonium griseoviride $(3530)$ & 1994 & aveia & 0,75 & - & 97,4 \\
\hline Acremonium kiliense (2459) & 1977 & folhedo & - & - & 102,7 \\
\hline Acremonium kiliense(3758) & 1997 & solo & 0,97 & + & 112,0 \\
\hline Acremonium kiliense (5131) & 2005 & endofítico da cana-de-açúcar & - & - & 109,3 \\
\hline Acremonium murorum (3652) & 1995 & lesão de cárie & NR & $\mathrm{NR}$ & NR \\
\hline Acremonium pteridii (4754) & 2003 & manguezal & - & - & 174,2 \\
\hline Acremonium roseolum (2508) & 1979 & tomate & NR & NR & NR \\
\hline Acremonium roseolum(4829) & 2004 & ninho de saúva & 0,93 & + & 111,1 \\
\hline Acremonium rutilum (2855) & 1994 & ar & NR & NR & NR \\
\hline Acremonium rutilum (3154) & 1989 & água marinha & - & - & 106,7 \\
\hline Acremonium strictum (2438) & 1977 & folhedo & 0,75 & + & 102,0 \\
\hline Acremonium strictum (2723) & 1982 & inseto & - & - & 100,0 \\
\hline Acremonium strictum (3070) & 1989 & hiperparasita phyllachora & 0,59 & + & 66,7 \\
\hline Acremonium strictum (3178) & 1990 & requeijão & - & - & 66,7 \\
\hline Acremonium strictum (3531) & 1994 & milho & 0,88 & + & 92,5 \\
\hline Acremonium strictum (3562) & 1994 & lesão de cárie & - & - & 90,9 \\
\hline Acremonium strictum (4164) & 1999 & rizosfera de girasol & - & - & 100,0 \\
\hline Acremonium strictum (5031) & 2005 & solo & 0,72 & + & 87,0 \\
\hline Acremonium terricola $(2765)$ & 1983 & rizosfera de cana-de-açúcar & - & + & 97,1 \\
\hline Acremonium vitellinum $(3190)$ & 1990 & lixa de coqueiro & NR & NR & NR \\
\hline
\end{tabular}

NR: não realizado, +: positivo, -: negativo 
de $10 \mathrm{~g}$ de glicose); c) meio A (meio $\mathrm{CN}$ adicionado de $10 \mathrm{~g}$ de amido). Após 15 dias a $28^{\circ} \mathrm{C} \pm 2^{\circ} \mathrm{C}$, a taxa de crescimento das espécies de Acremonium inoculadas em meio A foi comparada com a taxa observada nos meios $\mathrm{CN}$ e $\mathrm{CP}$, utilizando a fórmula Tx = A x 100/G, onde A representa o diâmetro da respectiva colônia no meio A, e G representa o diâmetro da colônia no meio $\mathrm{CP}$, onde o crescimento é considerado de $100 \%$.

Fosfolipase. A detecção de fosfolipase foi realizada de acordo com Price e cols ${ }^{16}$.

\section{RESULTADOS}

Viabilidade e confirmação taxonômica. Das 31 culturas de Acremonium preservadas sob óleo mineral, 26 (83,9\%) permaneceram viáveis e cinco (16,1\%) (URM1929, URM3190, URM3563, URM3652, URM3785) inviáveis devido ao não crescimento em caldo glicosado e em BDA contido em tubos. Das 26 culturas viáveis 24 (92,3\%) foram confirmadas taxonomicamente por apresentarem estruturas reprodutivas características de cada espécie ${ }^{469}$.

Protease. Das 24 culturas testadas, 12 (50\%) foram protease positivas, com nove (75\%) apresentando atividade em ambos os substratos, duas (16,7\%) (URM3530, URM4029) degradando apenas o substrato de caseína do leite e uma (8,3\%) (URM2765) apenas o substrato de gelatina (Tabela 1). Destas 11 culturas, três apresentaram ZA entre 0,93 e 0,97 (muito fraca), três com ZA entre 0,88 e 0,82 (fraca), quatro apresentaram ZA entre 0,75 e 0,72 (forte) e uma cultura (URM3070) demonstrou produção de protease muito forte com $\mathrm{ZA}=0,59$.

Amilase. A taxa de crescimento de 16 (66,7\%) das 24 culturas de Acremonium testadas apresentaram valor igual ou superior a $100 \%$, indicativo de atividade amilolítica.

Fosfolipase. Neste estudo, nenhuma das culturas apresentou atividade fosfolipásica.

\section{DISCUSSÃO}

Os resultados demonstram que espécies de Acremonium preservadas sob óleo mineral em coleções de cultura mantêm a viabilidade com estruturas reprodutivas após longos períodos de estocagem. Rodrigues e cols ${ }^{18}$ obtiveram $100 \%$ de viabilidade de 14 culturas de Acremonium preservadas pelo método de água destilada esterilizada proposto por Castelanni ${ }^{2}$ por seis a 24 meses, demonstrando a eficácia da preservação de culturas de Acremonium por ambos os métodos.

Mahgoub $^{14}$, estudando amostras de Acremonium kiliense como agentes de eumicetomas, verificou que a maioria das amostras apresentou atividade proteásica positiva ou fraca em meio contendo caseína do leite como substrato e negativa em gelatina. Esses resultados discordam dos obtidos neste trabalho, uma vez que uma das três culturas de Acremonium kiliense (URM3758) foi positiva em ambos os substratos.
A atividade proteásica tem um importante papel na patogenicidade de fungos oportunistas ${ }^{21}$, sendo a produção por fungos patógenos reconhecida como um importante fator de virulência $^{1120}$. Acredita-se que o papel fisiológico das proteases durante a colonização do hospedeiro ocorre pela degradação das barreiras da pele e mucosa, digestão das proteínas para obtenção de nutrientes e ataque dos linfócitos e macrófagos, afetando a defesas imunes ${ }^{10}$.

Segundo Mahgoub ${ }^{14}$, espécies de Acremonium kiliense isoladas de amostras clínicas de eumicetomas não são capazes de hidrolisar amido, estando estes resultados divergindo dos obtidos no presente trabalho, onde três amostras desta espécie (URM2459, URM3758, URM5131) apresentaram-se capazes de produzir amilase.

Fosfolipídios e proteínas são os principais constituintes químicos da membrana da célula do hospedeiro. Conseqüentemente, enzimas capazes de hidrolisar essas classes químicas, como fosfolipases e proteases, estão envolvidas no processo de ruptura da membrana celular ${ }^{19}$.

Na literatura não foram encontradas citações de produção de fosfolipase por espécies de Acremonium, contudo, a observação de que a fosfolipase também é relatada na virulência em fungos de interesse médico, semelhante a Candida albicans ${ }^{13}$ e Aspergillus fumigatus $^{7}$, faz com que essa enzima esteja envolvida na patogenicidade de infecções causadas por fungos.

Esta é a primeira vez que foram caracterizadas quanto à detecção de protease e amilase 24 culturas de Acremonium mantidas na Coleção de Culturas URM, demonstrando os diferentes padrões entre as mesmas culturas.

\section{AGRADECIMENTOS}

Os autores agradecem ao RENNEBRA-CNPq/MCT (Processo 552410/2005-5) pelo suporte financeiro.

\section{REFERÊNCIAS}

1. Anadolu R, Hilmioglu S, Oskay T, Boyvat A, Peksari Y, Gürgey E. Indolent Acremonium strictum infection in an immunocompetent patient. International Journal of Dermatology 40: 451-453, 2001.

2. Castellani A. Maintenance and cultivation of common pathogenic fungi of man in sterile distilled water. Further researches. Journal of Tropical Medicine and Hygiene 70: 181-184, 1967.

3. Cordeiro Neto F, Perssoni RAB, Figueiredo-Ribeiro RCL. Fungos produtores de inulinases isolados da rizosfera de Asteraceae herbácea do cerrado. Revista Brasileira de Ciência do Solo 21: 149-153, 1997.

4. Domsch, KH, Gams W, Traute-Heide A. Compendium of soil fungi. IHW-verlang Press, Germany, 1993.

5. Fincher RME, Fisher JF, Lovell RD, Newman CL, Espinel-Ingroff A, Shadomy HJ. Infection due to the fungus Acremonium (Cephalosporium). Medicine 70: 398-409, 1991.

6. Gams W. Cephalosporium - artige Schimmelpilze (Hyphomyceto). G. Fisher, Stuttgart, 1971.

7. Ganendren R, Widmer F, Singhal V, Wilson C, Sorrell T, Wright L. In vitro Antifungal Activities of Inhibitors of Phospholipases from the Fungal Pathogen Cryptococcus neoformans. Antimicrobial Agents and Chemotherapy. 48: 1561-1569, 2004. 
8. Guarro J, Gams W, Pujol I, Gene J. Acremonium species: new emerging fungal opportunists-in vitro antifungal susceptibilities and review. Clinical Infectious Diseases 25: 1222 - 1229, 1997.

9. Hoog GS, Guarro J, Gená J, Figueras MJ. Atlas of Clinical fungi. Universitat Rovira I Virgili Press, Netherlands, 2000.

10. Hube B. Exocellular proteases of human pathogenic fungi. Contributions to Microbiology 5: 126-137, 2000 .

11. Kwon-Chung KJ, Lehman D, Good C, Magee PT. Genetic evidence for role of extracellular proteinase in virulence of Candida albicans. Infection and Immunity 49: 570-575, 1985.

12. Lacaz CS, Porto E, Martins JEC, Heins-Vacarri EM, Melo NK. Tratado de Micologia Médica. Sarvier Press, São Paulo, 2002

13. Leidich SD, Ibrahim AS, Fu Y, Koul A, Jessup C, Vitullo J, Fonzi W, Mirbod F, Nakashima S, Nozawa Y, Ghannoum MA. Cloning and disruption of caPLB1, a phospholipase B gene involved in the pathogenicity of Candida albicans. Journal of Biological Chemistry 273: 26078-26086, 1998.

14. Mahgoub ES. Medical management of mycetoma. Bulletin of the World Health Organization 54: 303-310, 1976.
15. Ogawa H, Nozawa Y, Roja Navanich V. Fungal enzymes in the pathogenesis of fungal infection. Journal of Medical and Veterinary Mycology 30: 189-196, 1992.

16. Price MF, Walkison ID, Gentry LO. Plate method for detection of phospholipase activity in Candida albicans. Sabouraudia 20: 7-14, 1982.

17. Rhodes JC. Virulence factors in fungal pathogens. Microbiology science 5: 252-254, 1988.

18. Rodrigues EG, Lírio VS, Lacaz CS. Preservação de fungos e actinomicetos de interesse médico em água destilada. Revista do Instituto de Medicina Tropical de São Paulo 34: 159-165, 1992.

19. Salyers A, Witt D. Bacterial pathogenesis: a molecular approach. ASM Press Washington, DC, 1994.

20. Sartafi J, Boucias DG, Latge JP. Antigens of Aspergillus fumigatus produced in vivo. Journal of Medical and Veterinary Mycology 33: 9-14, 1995.

21. Serda SK, Yucel A. Phospholipase and protease activities in clinical Candida isolates with reference to the sources of strains. Mycoses. 45: 160-165, 2002.

22. Sherf AF. A method for maintaining Phytomonas sepedonica in culture for long periods without transfer. Phytopatology 33: 330-332, 1943. 